\title{
Hydroxy, carboxylic and amino acid functionalized superparamagnetic iron oxide nanoparticles: Synthesis, characterization and in vitro anti-cancer studies
}

\author{
DILAVEEZ REHANA ${ }^{\mathrm{a}, \mathrm{b}}$, AZEES KHAN HALEEL ${ }^{\mathrm{a}}$ and AZIZ KALILUR RAHIMAN ${ }^{\mathrm{a}, *}$ \\ aPost-Graduate and Research Department of Chemistry, The New College (Autonomous), \\ Chennai 600 014, India \\ bJustice Basheer Ahamed Sayeed College for Women (Autonomous), Chennai 600 018, India \\ e-mail: akrahmanjkr@gmail.com
}

MS received 5 September 2014; revised 28 February 2015; accepted 4 March 2015

\begin{abstract}
Superparamagnetic iron oxide nanoparticles were synthesized by simple co-precipitation method and modified with different coating agents such as ascorbic acid, hexanoic acid, salicylic acid, L-arginine and L-cysteine. The synthesized nanoparticles were characterized by various techniques such as FT IR, XRD, VSM, SEM, TEM and thermal analysis. Both bare and coated magnetites were of cubic spinel structure and spherical in shape. All the magnetite nanoparticles showed superparamagnetic behaviour with high saturated magnetization. In vitro cytotoxicity test of bare and coated nanoparticles was performed using adenocarcinoma cells, A549. Cell viability of bare and L-arginine coated magnetite nanoparticles showed $\mathrm{IC}_{50}$ value of 31.2 $\mu \mathrm{g} / \mathrm{mL}$ proving the compatibility of nanocarriers when compared to others. Hence, L-arginine coated nanoparticles were used for loading the drug paclitaxel and the observed $\mathrm{IC}_{50}$ value $(7.8 \mu \mathrm{g} / \mathrm{mL})$ shows its potent anti-proliferative effect against A549 lung cancer cell lines. Thus, it can be speculated that the drug paclitaxel loaded L-arginine coated nanoparticles could be used as an effective drug carrier for the destruction of cancer cells.
\end{abstract}

Keywords. Magnetite nanoparticles; acid-coated magnetite nanoparticles; cytotoxicity; DNA fragmentation.

\section{Introduction}

In recent years, nanoparticles have attracted considerable attention because of their potential medicinal applications such as cellular therapy involving cell labelling and targeting as a tool for cell biology research to separate and purify cell population, tissue repair, targeted drug delivery, magnetic resonance imaging and hyperthermia for cancer treatment. ${ }^{1}$ Most of these applications require the nanoparticles to be uniform in size and shape and well-dispersed in solvents, which are generally controlled by synthesis method. ${ }^{2}$ The magnetic nanoparticles have gained increasing attention for use in biomedical applications. Among these, iron oxide is one of the most important transition metal oxides. Sixteen pure phases of iron oxide i.e.,oxide, hydroxide or oxy-hydroxides are known to date; these are $\mathrm{Fe}(\mathrm{OH})_{3}$, $\mathrm{Fe}(\mathrm{OH})_{2}, \mathrm{Fe}_{5} \mathrm{HO}_{8}-4 \mathrm{H}_{2} \mathrm{O}, \mathrm{Fe}_{3} \mathrm{O}_{4} \mathrm{FeO}$, five polymorphs of $\mathrm{FeOOH}$, and four $\mathrm{Fe}_{2} \mathrm{O}_{3}$. Magnetite $\left(\mathrm{Fe}_{3} \mathrm{O}_{4}\right)$ is a black ferromagnetic mineral containing both $\mathrm{Fe}(\mathrm{II})$ and $\mathrm{Fe}(\mathrm{III}) .{ }^{3}$ It has cubic inverse spinel structure with fcc close-packed oxygen and iron ions occupying interstitial tetrahedral and octahedral sites. ${ }^{4}$ In the nano-realm,

\footnotetext{
*For correspondence
}

$\mathrm{Fe}_{3} \mathrm{O}_{4}$ particles exhibit superparamagnetic behaviour at room temperature, i.e., they magnetize strongly under the applied magnetic field but do not retain this property once the field is removed. This nature makes them suitable for biomedical applications. ${ }^{5}$ Superparamagnetic iron oxide has been recognized as a promising tool for site specific delivery of drugs and diagnostic agent. ${ }^{6}$ To date, these nanoparticles are known to be low in toxicity and biocompatibile. These features make it an ideal material for in vitro studies. ${ }^{7}$

The surface functionalization of magnetite nanoparticles with a biological or chemical agent which binds to a specific target has been of great interest in recent years. ${ }^{8}$ The functionalization of nanoparticles improve their biocompatibility, avoid aggregation among the particles by magnetic forces and provides the specific functionilization to cancer cells. ${ }^{9}$ To impart functionality and conjugate with biologically active agents, iron oxide nanoparticles are usually coated with functional groups on their surface, such as phosphate, sulphate, carboxylate, etc. Of these functional groups, carboxylate is the strongest binder. The carboxyl/hydroxyl group gets chemisorbed to the nanoparticles forming a carboxylate group with $\mathrm{Fe}-\mathrm{OH}$ molecules leaving 
any other group present for various purposes. ${ }^{10}$ Several anti-cancer drugs including doxorubicin, 5-fluorouracil, dexamethasone and paclitaxel have been successfully formulated using nanomaterials, which can either be integrated in the matrix of particles or attached to the particle surface. ${ }^{11}$ Drug delivery using superparamagnetic nanoparticles can be manipulated by external magnetic field. ${ }^{12}$ The drug loaded magnetic nanoparticles have been investigated for various biomedical application such as DNA separation, drug delivery, magnetic resonance imaging, and hyperthermia. ${ }^{13}$

This paper describes the synthesis of non-toxic and biocompatible $\mathrm{Fe}_{3} \mathrm{O}_{4}$ nanoparticles functionalized with different acids such as ascorbic acid, hexanoic acid, salicylic acid, L-arginine and L-cysteine by co-precipitation method, which allows targeted drug delivery to the cancer cell lines thereby reducing the systemic toxicity of the anti-cancer drug. The effect of the crystal structure, morphology and magnetic properties of bare and modified $\mathrm{Fe}_{3} \mathrm{O}_{4}$ were investigated. Further, all the acid coated nanoparticles and paclitaxel drug loaded Larginine coated nanoparticles were evaluated for their in vitro cytotoxicity on adenocarcinoma cells A549 using MTT assay. It was found that positively charged Larginine coated nanoparticles demonstrated a significant amount of cytotoxicity with $\mathrm{IC}_{50}$ value of 31.2 $\mu \mathrm{g} / \mathrm{mL}$ when compared to the negatively charged carboxylic and hydroxy acids (ascorbic acid, salicylic acid or hexanoic acid) coated nanoparticles. The nanoparticles functionalized with L-arginine exhibit highest cytotoxic effect, and hence subjected to DNA fragmentation by agarose gel electrophoresis.

\section{Experimental}

\subsection{Materials}

Ferrous chloride tetrahydrate $\left(\mathrm{FeCl}_{2} \cdot 4 \mathrm{H}_{2} \mathrm{O}\right)$ and ferric chloride anhydrous $\left(\mathrm{FeCl}_{3}\right)$ were used as the precursor and purchased from Sigma-Aldrich. Ascorbic acid, hexanoic acid, salicylic acid, L-arginine and L-cysteine were used as coating agent and purchased from Merck. All the materials were analytical grade and used without further purification. Solvents were dried and purified before being used according to standard procedure.

\subsection{Synthesis of magnetic nanoparticles}

Synthesis of magnetite $\left(\mathrm{Fe}_{3} \mathrm{O}_{4}\right)$ nanoparticles was carried out by chemical co-precipitation method in a nitrogen atmosphere as per the reported procedure with little modification. ${ }^{2} \mathrm{FeCl}_{2} \cdot 4 \mathrm{H}_{2} \mathrm{O}$ and $\mathrm{FeCl}_{3}$ with the molar ratio of ferric to ferrous ion 0.01:0.007 were dissolved in $100 \mathrm{~mL}$ deionised water and $25 \mathrm{wt} \% \mathrm{NH}_{4} \mathrm{OH}$ was added slowly to achieve complete precipitation of iron oxide. Coating agent (Ascorbic acid, hexanoic acid, salicylic acid, L-arginine or L-cysteine) was added at a concentration of $0.07 \%$ to the above solution with vigorous stirring. On addition of the hydroxy and carboxylic acid, the solution became yellow in colour which then turned to black on vigorous stirring. When the amino acids were added, the solution became dark blue which then turned to black on vigorous stirring. The modified magnetite nanoparticles were filtered, thoroughly washed with deionized water to remove chloride ions, then washed several times with ethanol to remove excess coating agent, and finally dried in vacuum at $80^{\circ} \mathrm{C}$ for $24 \mathrm{~h}$. The bare magnetite nanoparticles were also prepared by adopting same procedure without adding coating agent. The samples are denoted as S-S7; S-Bare magnetite nanoparticles, S1-Ascorbic acid coated magnetite nanoparticles, S2-Hexanoic acid coated magnetite nanoparticles, S3-Salicylic acid coated magnetite nanoparticles, S4-L-arginine coated magnetite nanoparticles, S5-L-cysteine coated magnetite nanoparticles, S6-Drug paclitaxel, S7-Paclitaxel loaded L-arginine coated magnetite nanoparticles.

\subsection{Characterization}

FT IR measurements were carried out on Shimadzu IR460 spectrophotometer in the range $4000-400 \mathrm{~cm}^{-1}$ using $\mathrm{KBr}$ pellets. The crystalline structure of the nanoparticles was determined using X-ray diffraction (XRD) on a Siefert Analyze diffractometer operated at $40 \mathrm{Kv}$ and $35 \mathrm{~mA}$ with $\mathrm{Cu} \mathrm{K} \alpha$ radiation $(\lambda=0.15406$ $\AA$ ). The hydrodynamic size and the zeta potential distribution of nanoparticles were measured on Malvern Zetasizer Ver 6.20 (Malvern instruments, UK). Magnetization $\left(\mathrm{M}_{\mathrm{S}}\right)$ values of dried magnetite nanoparticles were evaluated at room temperature by Lakeshore vibrating sample magnetometer model 7410 . The morphology was studied by a Field Emission Scanning Electron Microscope (FESEM) at 10 to $30 \mathrm{kV}$ (Hitachi SU6600). The particle size and size distribution were calculated from TEM image of nanoparticles on Philips Technai at $180 \mathrm{kV}$. The thermal stability was determined by thermogravimetric analysis (Netzsch STA 409 TGA/ DSC). The thermogram was recorded for $5 \mathrm{mg}$ of powder sample at a heating rate of $10^{\circ} \mathrm{C}$ per min in the temperature of $30-800^{\circ} \mathrm{C}$ under nitrogen atmosphere.

\subsection{Cytotoxitcity}

Human lung adenocarcinoma (A549) cancer cell lines were obtained from National Centre for Cell Sciences 
(NCCS), Pune, India. The cells were maintained in Minimal Essential Media supplemented with $10 \%$ Fetal Bovine Serum (FBS), penicillin $(100 \mu \mathrm{g} / \mathrm{mL})$ and streptomycin $(100 \mu \mathrm{g} / \mathrm{mL})$ in a humidified atmosphere of $5 \% \mathrm{CO}_{2}$ at $37^{\circ} \mathrm{C}$.

The anti-cancer activity of bare and coated magnetite nanoparticles was determined by MTT (3-(4,5-dimethyl2-thiazolyl)-2,5-diphenyltetrazolium bromide) assay. The A549 cells $\left(1 \times 10^{5} /\right.$ well $)$ were plated in $0.2 \mathrm{~mL}$ of medium/well in 96-well plate and treated with bare and coated magnetite nanoparticles suspension at different concentrations $(10-1000 \mu \mathrm{g} / \mathrm{mL})$ and incubated for 72 $\mathrm{h}$ at $37^{\circ} \mathrm{C}$ in a $5 \% \mathrm{CO}_{2}$ incubator for better cell attachment. Thereafter, the wells were washed with warm phosphate buffered saline solution and incubated again for $4 \mathrm{~h}$ with DMEM containing $25 \mu \mathrm{L}$ of $5.5 \mathrm{mg} / \mathrm{mL}$ MTT solution. After discarding the culture medium, 1 $\mathrm{mL}$ of DMSO was added to dissolve the precipitate, and the resultant solution was measured at $540 \mathrm{~nm}$. The inhibitory concentration value $\left(\mathrm{IC}_{50}\right)$ was determined from the absorbance versus the concentration curves. The experiment was carried out in triplicate and the values are expressed as mean $\pm \mathrm{SD}$.

\subsection{DNA Fragmentation}

Inter-nucleosomal cleavage of DNA was analysed as described previously. ${ }^{14}$ The cells were incubated with L-arginine coated nanoparticles for $48 \mathrm{~h}$ followed by cell detachment using trypsin-EDTA and washed with phosphate buffered saline solution. The cell pellets were incubated with $200 \mu \mathrm{L}$ at $5 \% \mathrm{CO}_{2}$ with protein precipitation solution. After centrifugation, the supernatant containing the DNA was separated and mixed with 600 $\mu \mathrm{L}$ isopropanol followed by centrifugation and mixing the pellets with DNA sample solution at $65^{\circ} \mathrm{C}$ for $1 \mathrm{~h}$. DNA bands were separated using $2 \%$ agarose gel electrophoresis containing ethidium bromide and visualized using UV trans illuminator. The untreated cells were used as a negative control.

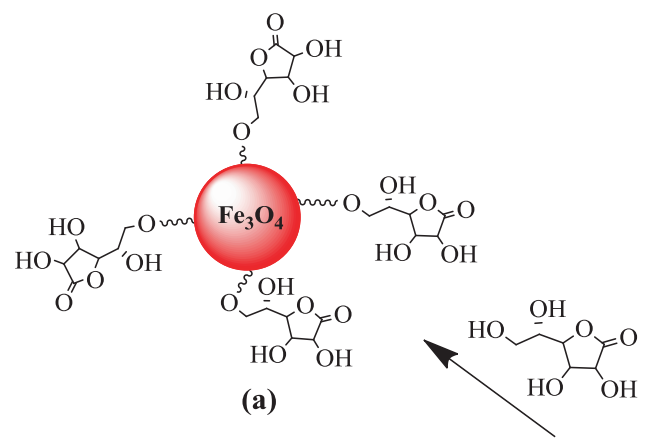

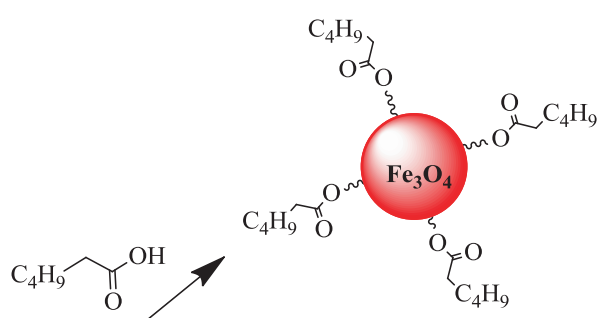

(b)

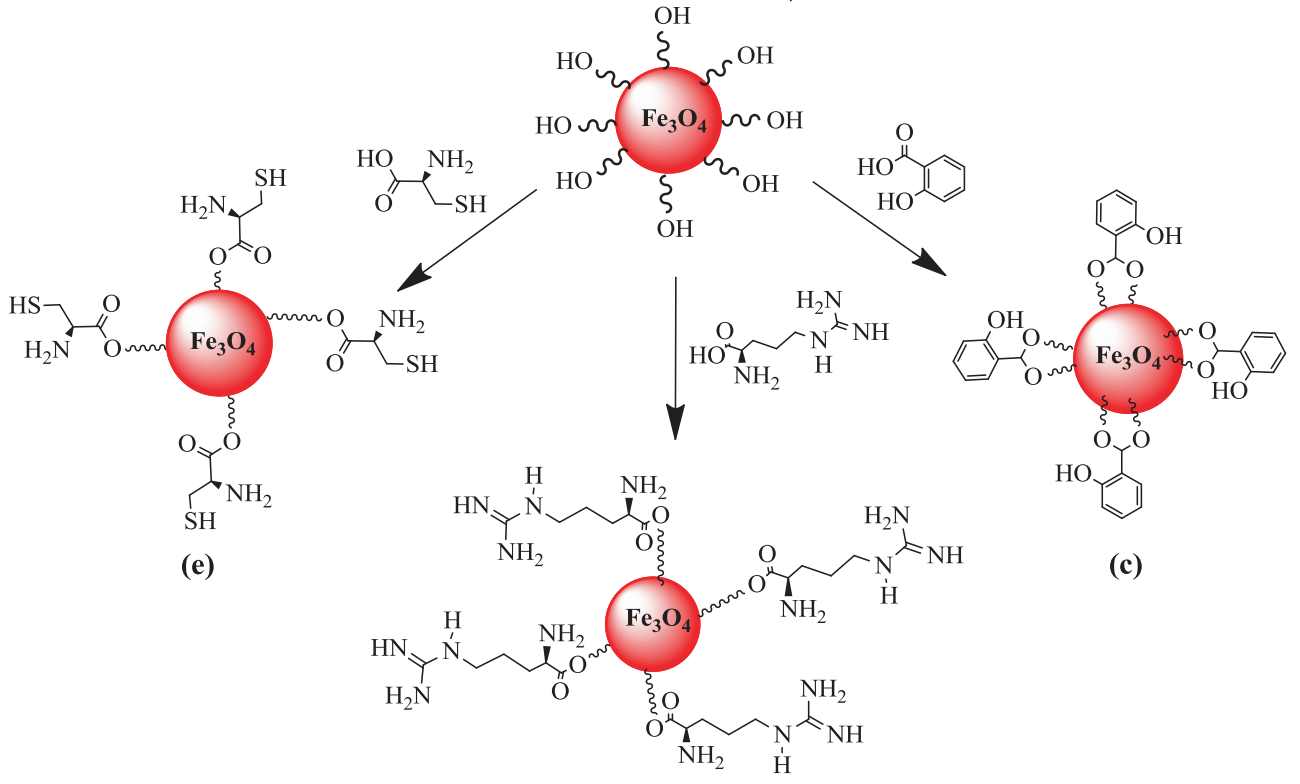

(d)

Figure 1. Schematic representation of esterification of iron oxide nanoparticles with different coating agents (a) Ascorbic acid; (b) Hexanoic acid; (c) Salicylic acid; (d) L-Arginine; and (e) L-Cysteine. 


\section{Results and Discussion}

Iron oxide nanoparticles were synthesized by coprecipitation method using aqueous $\mathrm{Fe}^{2+} / \mathrm{Fe}^{3+}$ by the addition of a base under inert atmosphere at elevated temperature. A black coloured precipitate was obtained which was washed and dried. There was no colour change between bare and coated iron oxide nanoparticles. Flow of nitrogen not only protects oxidation but also reduces the size of the particle. Ammonium hydroxide plays a key role in the formation of $\mathrm{Fe}_{3} \mathrm{O}_{4}$. It acts as a $\mathrm{pH}$ buffer and reacts with water to give constant supply of $\mathrm{OH}^{-}$ions. ${ }^{15}$ The reaction involved in this process is expressed as follows. ${ }^{16}$

$$
\begin{aligned}
\mathrm{Fe}^{2+}+ & 2 \mathrm{Fe}^{3+}+8 \mathrm{OH}^{-} \\
\rightarrow & \mathrm{Fe}_{3} \mathrm{O}_{4} \text { (black colloidal particles) }+4 \mathrm{H}_{2} \mathrm{O} \\
& \mathrm{Fe}_{3} \mathrm{O}_{4}+0.25 \mathrm{O}_{2}+4.5 \mathrm{H}_{2} \mathrm{O} \rightarrow 3 \mathrm{Fe}(\mathrm{OH})_{3}
\end{aligned}
$$

During the coating process, acid was chemically adsorbed on to the magnetite nanoparticles which then undergo esterification between the hydroxyl, amino and carboxyl groups of the different coating agents. Schematic representations of functionalized nanoparticles are shown in figure 1. It is reported that magnetic nanoparticles prepared by co-precipitation method have a number of hydroxyl groups on the surface. ${ }^{17}$ Hence, the interaction between the coating material containing carboxyl or hydroxyl groups which acts as a hydrogen bond acceptor or donor with the magnetite nanoparticles takes place through hydrogen bond. ${ }^{18}$

\subsection{FT IR analysis}

FT IR spectra of bare and coated magnetite nanoparticles are shown in figure 2. The characteristic band at $590 \mathrm{~cm}^{-1}$ indicative of $\mathrm{Fe}-\mathrm{O}$ present in $\mathrm{Fe}_{3} \mathrm{O}_{4}{ }^{16}$ This band is shifted to $574-584 \mathrm{~cm}^{-1}$ for acid coated materials indicating successful functionalization on the surface of the magnetite nanoparticles. These bands are attributed to the intrinsic vibration of iron ion in tetrahedral and octahedral sites of spinel structure, respectively. It was also reported that the magnetite nanoparticles take up hydroxy groups on the surface upon contact with aqueous phase through adsorption of $\mathrm{OH}^{-}$ ion on $\mathrm{Fe}$ and $\mathrm{H}^{+}$on $\mathrm{O} .{ }^{19}$ The band at $1633 \mathrm{~cm}^{-1}$ is assigned to the $\mathrm{OH}$ stretching vibration of $\mathrm{Fe}_{3} \mathrm{O}_{4}$. The appearance of band at $1600-1630 \mathrm{~cm}^{-1}$ corresponds to stretching vibration of $\mathrm{C}=\mathrm{O}$ for the coated nanoparticles. The band at $2840-2855 \mathrm{~cm}^{-1}$ and $2920-2955$

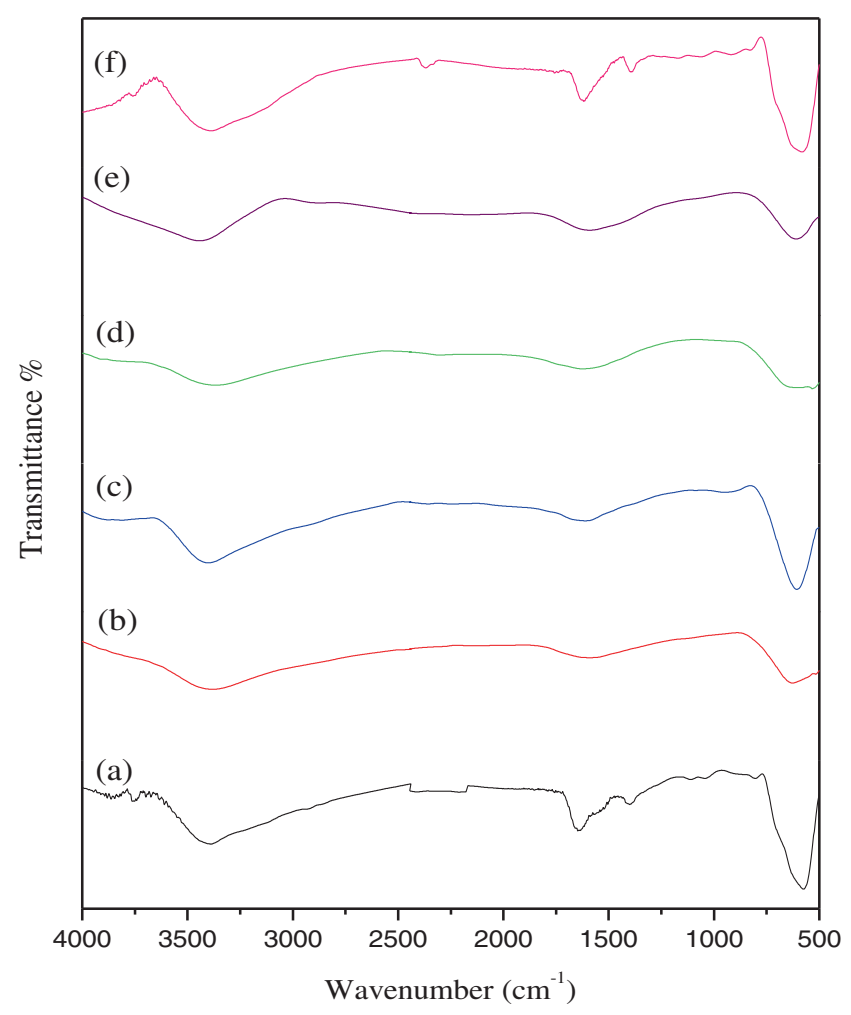

Figure 2. FT-IR spectra of (a) $\mathrm{Fe}_{3} \mathrm{O}_{4}$ nanoparticles; and nanoparticles coated with (b) Ascorbic acid; (c) Hexanoic acid; (d) Salicylic acid; (e) L-Arginine; (f) L-Cysteine.

$\mathrm{cm}^{-1}$ are assigned to $\mathrm{CH}_{2}$ symmetric and asymmetric stretching of all the functionalized nanoparticles except salicylic acid coated nanoparticles. ${ }^{20}$ The band at 1400 $1431 \mathrm{~cm}^{-1}$ and $1530-1552 \mathrm{~cm}^{-1}$ corresponds to the asymmetric and symmetric stretching vibrations of carboxyl group $\left(\mathrm{COO}^{-}\right)$of coating agents except ascorbic acid. Here, two binding modes have been suggested. In one mode, carboxylate is connected to the surface through one oxygen atom giving rise to symmetric and asymmetric vibrations, while in the other mode it is bound symmetrically to the surface giving rise to only stretching vibrations. The combination of molecules bonded symmetrically and molecules bonded at an angle by the carboxylic acid on the surface of magnetite nanoparticles is thus explained. ${ }^{21}$ However, the ascorbic acid coated material showed two strong bands at 1024 and $1091 \mathrm{~cm}^{-1}$ corresponding to the symmetric stretching mode of $\mathrm{C}-\mathrm{O}-\mathrm{C}$ vibration. The $\mathrm{L}$-arginine coated nanoparticles exhibit a band at $1637 \mathrm{~cm}^{-1}$ corresponding to $\mathrm{NH}$ bending and a broad band could be visualized in the range $3377-3398 \mathrm{~cm}^{-1}$ indicative of the presence of $\mathrm{NH}_{2}$ and $\mathrm{OH}$ group on the surface of the nanoparticles. The observed sharp band at 2360 $\mathrm{cm}^{-1}$ for L-cysteine functionalized magnetite nanoparticles is due to the presence of SH onto the surface of nanoparticles. ${ }^{22}$ 


\subsection{XRD analysis}

Powder XRD analysis revealed information about crystallographic structure, chemical composition and physical properties of the synthesized nano materials (figure 3). XRD pattern of magnetite exhibit the characteristic $110,220,311,400,422,511$ and 540 peaks of $\mathrm{Fe}_{3} \mathrm{O}_{4}$ crystal with a cubic spinel structure at $\sim 2 \theta$ of $30^{\circ}, 35^{\circ}, 43^{\circ}, 53^{\circ}, 57^{\circ}$ and $74^{\circ}$, respectively. ${ }^{2}$ Crystallinity and morphology of bare and coated iron oxide nanoparticles have been affected by different groups such as phosphates, carboxyl etc have also been reported. ${ }^{23}$ The most intense peak (311) appeared for both bare and acid functionalized $\mathrm{Fe}_{3} \mathrm{O}_{4}$ corresponds to reflection of $\mathrm{Fe}_{3} \mathrm{O}_{4}$ related to the mean size of the crystal according to Scherrer equation. ${ }^{16}$ The XRD pattern of the coated $\mathrm{Fe}_{3} \mathrm{O}_{4}$ materials indicate that the coating agent does not significantly affect the crystal structure

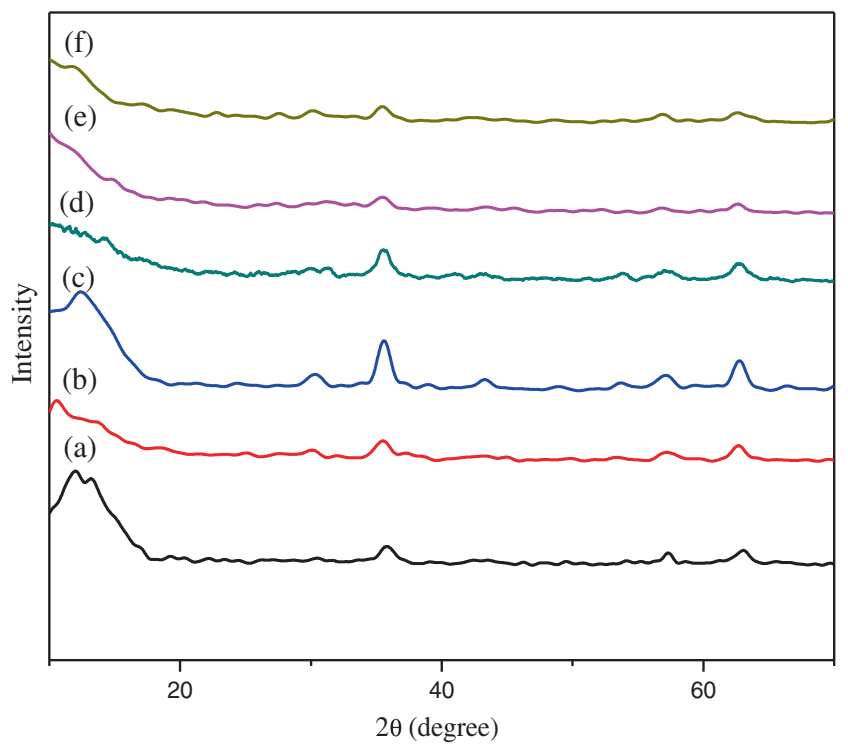

Figure 3. $\mathrm{XRD}$ pattern of (a) $\mathrm{Fe}_{3} \mathrm{O}_{4}$ nanoparticles; and nanoparticles coated with (b) Ascorbic acid; (c) Hexanoic acid; (d) Salicylic acid; (e) L-Arginine; (f) L-Cysteine. of the magnetite nanoparticles. The $\mathrm{Fe}_{3} \mathrm{O}_{4}$ peak (110) weakened in the coated material which is probably caused by the coating of different acids on the surface of magnetite nanoparticles.

However, XRD pattern of the coated magnetite nanoparticles depicted same peaks but the intensity varied due to the organic material present in it proving that coating agent helps in reducing the crystalline size without affecting the crystal structure. The peaks such as 311,400 and 422, of the coated $\mathrm{Fe}_{3} \mathrm{O}_{4}$ nanoparticles were selected for good fit correlation, half maximum width, average crystalline size and size distribution using Scherrer equation which resulted in error due to low fit correlation and poor crystallization. ${ }^{24}$

\subsection{Zeta potential and particle size measurements}

The stability of the nanoparticles were characterized by zeta potential value (figure 4). A lower zeta potential value means less charge and may be related to shorter adsorption time. ${ }^{10}$ L-Arginine functionalized nanoparticles do not exhibit good stabilization due to the fact that they do not possess electrostatic stabilization but have steric stabilization and hence have less zeta potential value of $3.8 \mathrm{mV}$. Hexanoic acid coated iron oxide nanoparticles have zeta potential value of $21.2 \mathrm{mV}$ and are also unstable; this may be due to the agglomeration of the nanoparticles. L-Arginine due to steric stabilization property and also the positive surface charge on the amino group plays a critical role in non-specifically sticking to the cells, entering into it and destroying it.

The average particle size measured by dynamic light scattering (DLS) analysis for L-arginine and hexanoic acid coated iron oxide nanoparticles are $30 \mathrm{~nm}$ and $195 \mathrm{~nm}$, respectively (figure 5). Particles were seen to aggregate due to strong dipole interaction, coating with pendant functional groups imparted stability by electrostatic repulsion. In the case of L-arginine coated
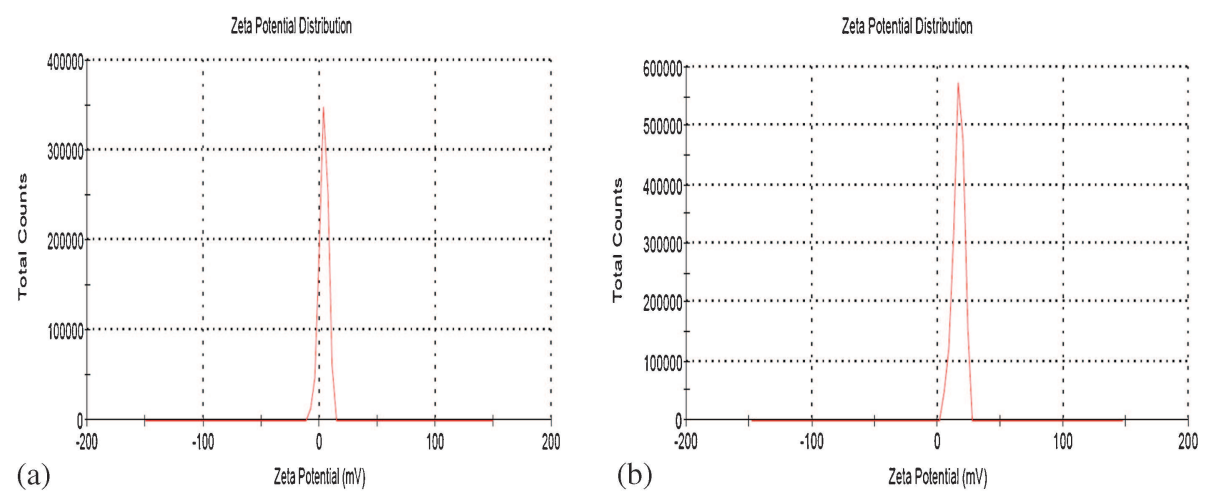

Figure 4. The zeta potential measurement of (a) L-Arginine coated $\mathrm{Fe}_{3} \mathrm{O}_{4}$ nanoparticles; (b) Hexanoic acid coated $\mathrm{Fe}_{3} \mathrm{O}_{4}$ nanoparticles. 

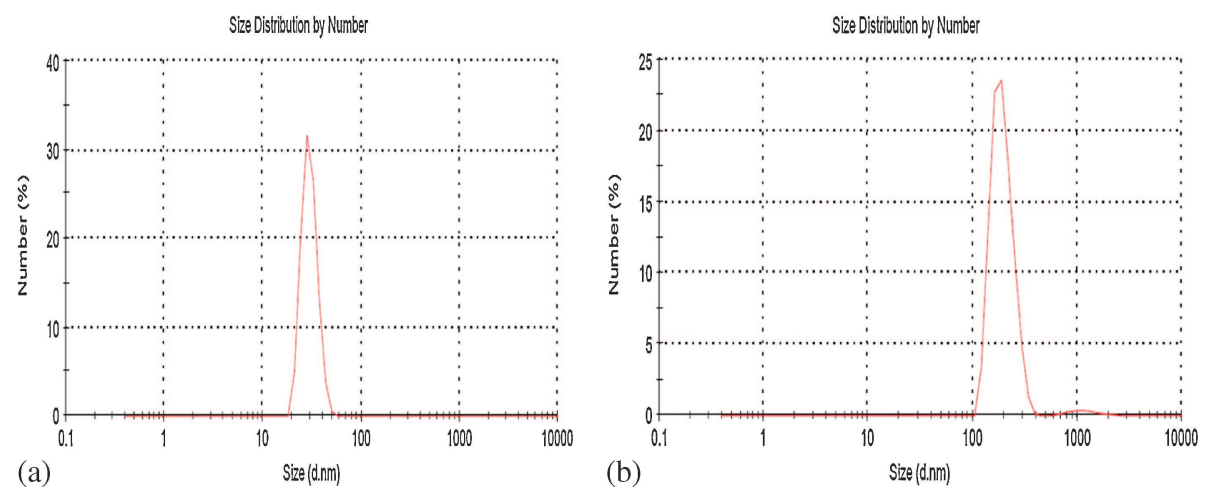

Figure 5. The particle size distribution of (a) L-Arginine coated $\mathrm{Fe}_{3} \mathrm{O}_{4}$ nanoparticles; and (b) Hexanoic acid coated $\mathrm{Fe}_{3} \mathrm{O}_{4}$ nanoparticles.

nanoparticles the strong hydrogen bonding between the surface and the coating agent reflects a decrease in the positive zeta potential and the small size favours the penetration into the cancer cell line thereby inhibiting its growth. ${ }^{22}$ Thus, the size and the surface charge distribution of functionalized nanoparticles anticipated the anti-cancer activity.

\subsection{Magnetic properties}

At the atomic level, the magnetic properties originate from the quantum coupling including coupling between electron spin (S-S coupling) and the coupling between the electron spin and angular momentum of the electron orbital (L-S coupling). ${ }^{25}$ Paramagnetic materials have a tendency to align with the magnetic dipole with an external magnetic field due to their small positive susceptibility and their random orientation in the absence of magnetic field. Superparamagnetic materials have much larger susceptibility as the entire crystals aligns with the applied field. ${ }^{26}$ Figure 6 shows the relative magnetization curves of the bare and coated magnetite nanoparticles as a function of magnetic field. The samples exhibited superparamagnetic behaviour due to the symmetric hysteresis and saturation magnetization which means that they are attracted by external magnetic field but retain no residual magnetism when the external magnetic field is removed at room temperature. Table 1 shows coercivity and magnetization values of bare and coated magnetite nanoparticles. The coercivity

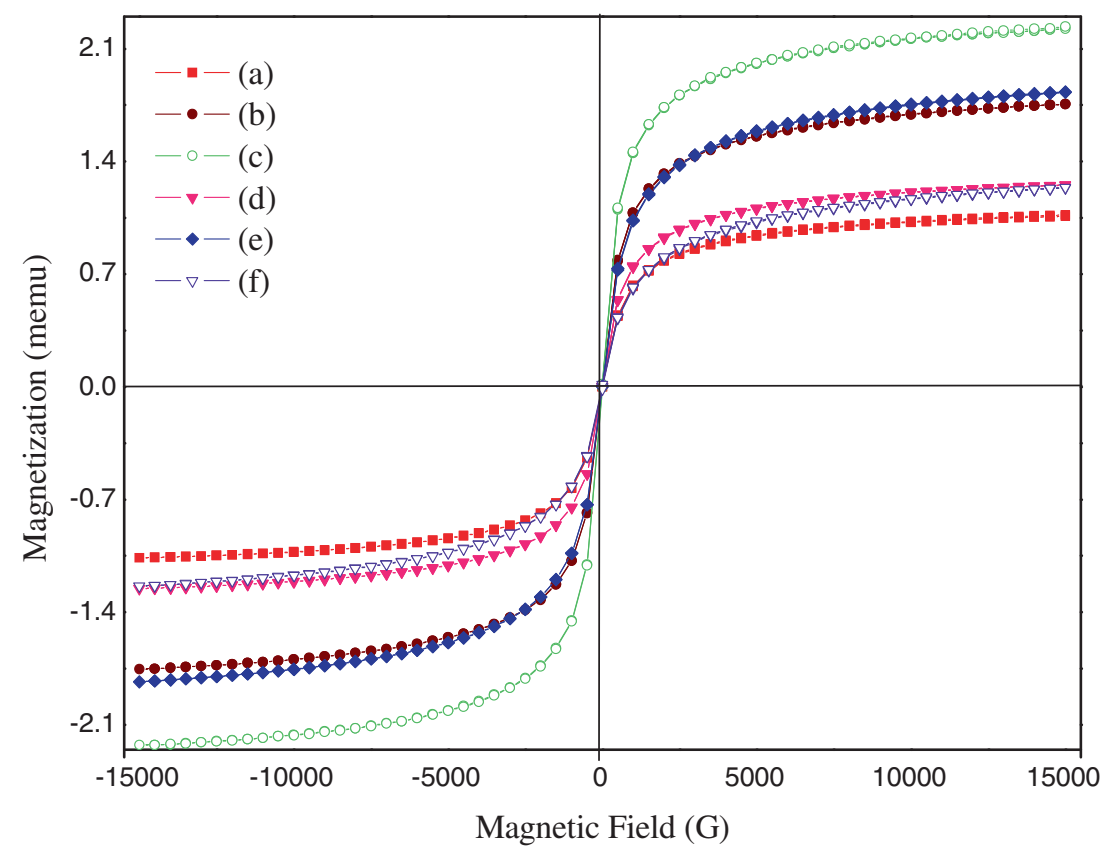

Figure 6. Magnetization curves of (a) $\mathrm{Fe}_{3} \mathrm{O}_{4}$ nanoparticles; and nanoparticles coated with (b) Ascorbic acid; (c) Hexanoic acid; (d) Salicylic acid; (e) L-Arginine; (f) L-Cysteine. 
Table 1. Coercivity and magnetization values for the synthesized nanoparticles.

\begin{tabular}{lcc}
\hline Samples & $\begin{array}{c}\text { Coercivity } \\
\text { HC }_{\mathbf{i}} \text { Gauss }\end{array}$ & $\begin{array}{c}\text { Magnetization } \\
\text { Ms (memu/mg) }\end{array}$ \\
\hline S & 1.5712 & 1.0645 \\
S1 & 3.5794 & 1.7552 \\
S2 & 5.1393 & 2.2312 \\
S3 & 0.9190 & 1.8323 \\
S4 & 1.8260 & 1.8323 \\
S5 & 16.334 & 1.2387 \\
\hline
\end{tabular}

and the remanence values are not discernible indicating a superparamagnetic behaviour. The Ms value of bare iron oxide nanoparticles is $1.0 \mathrm{memu} / \mathrm{mg}$ and that of acid coated iron oxide nanoparticles ranges between 1.2387 and $2.2312 \mathrm{memu} / \mathrm{mg}$. The lower magnetization value of bare magnetite when compared to the coated materials is due to easy transformation of magnetite to other phases with temperature. ${ }^{2}$ This difference in Ms value of the magnetic behaviour is mainly due to the decrease in particle size due to the reduction in crystallinity. The best way to increase the Ms value is to increase the crystalline size.

The high saturation magnetization of hexanoic acid coated nanoparticles indicated its good crystal structure. The changes of Ms value are correlated with the change of magnetic particle size and also the purity of the magnetite. ${ }^{27}$ Magnetization of the samples increases with external magnetic field which is the characteristic feature of superparamagnetic behaviour. This difference may give rise to non-collinear spin arrangement near the surface occurring due to the reduction of magnetic moment in iron oxide nanoparticles. ${ }^{28}$ Thus, such (a)

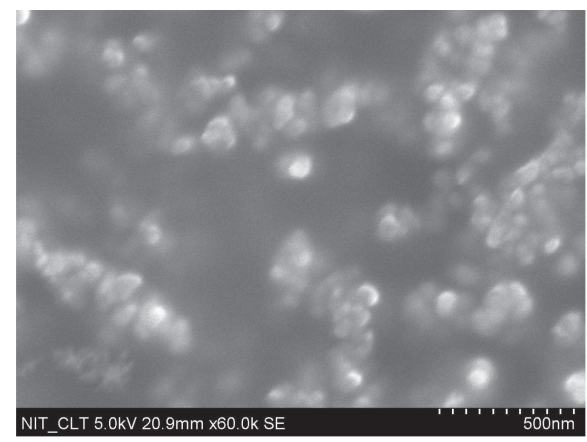

(c)

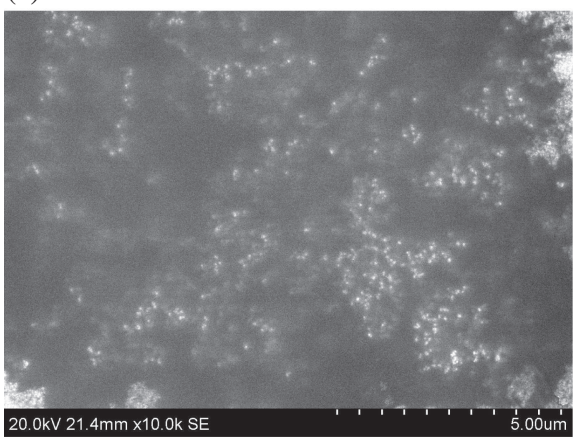

(e)

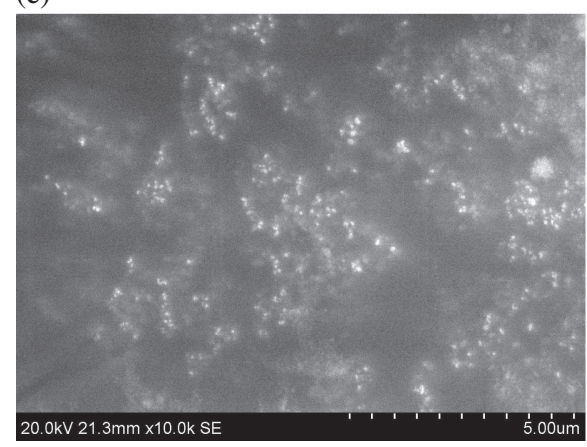

(b)

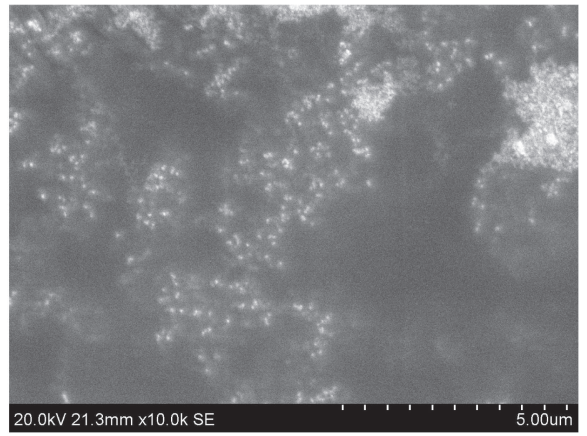

(d)

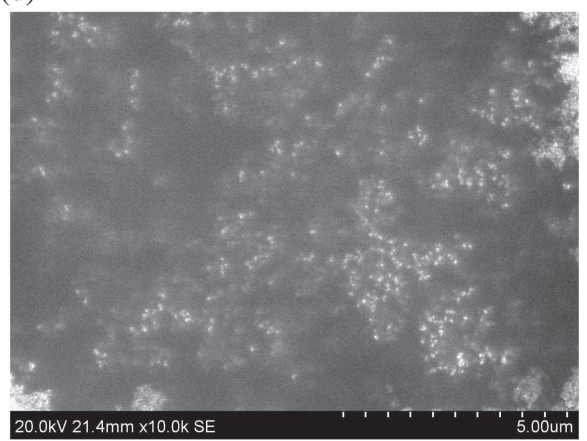

(f)

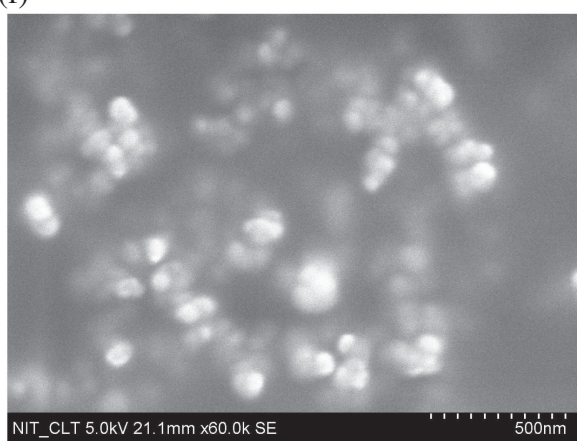

Figure 7. SEM images of (a) $\mathrm{Fe}_{3} \mathrm{O}_{4}$ nanoparticles; and nanoparticles coated with (b) Ascorbic acid; (c) Hexanoic acid; (d) Salicylic acid; (e) L-Arginine; (f) L-Cysteine. 
nanoparticles can be used as magnetic carriers which have good potential and broad application in drug delivery and hence can be used for the treatment of cancer in near future.

\subsection{SEM and TEM analysis}

FESEM micrographs (figure 7) display the morphology of the $\mathrm{Fe}_{3} \mathrm{O}_{4}$ nanoparticles. The shape of $\mathrm{Fe}_{3} \mathrm{O}_{4}$ nanoparticles is roughly spherical and with rough particle surface which will be useful for further surface coatings. The presence of rough surface suggests that these particles grow by aggregation of the small particles. The growth of large particles at the expense of smaller ones so as to achieve a minimum of total free energy by the tendency of solid phase in the system is described as Ostwald ripening. ${ }^{29}$ The images also indicate that these particles show good dispersion resulting from the protection of coatings on the surface of nanoparticles.

Transmission electron microscopy (TEM) images of L-arginine coated nanoparticles with different magnification shows that all the particles are spherical in shape (figure 8). TEM images revealed that the particle size for bare iron oxide nanoparticle is $31 \mathrm{~nm}$ and that of L-arginine coated nanoparticles was 26 $\mathrm{nm}$. This decrease in size is may be due to the coating agent, which prevents agglomeration and hence reduces the size of the nanoparticles. The nucleation rate per unit area is isotopic at the interphase between the iron oxide nanoparticles and hence gives rise to spherical shape.$^{30}$ However, small particles have larger surface area-to-volume ratio and represent a higher energy state than large particles. The crystallization of L-arginine coated magnetite nanoparticles showed no reduction in magnetic property and the growth was prevented because of the steric hindrance of coating agent.

\subsection{TGA-DSC analysis}

The results of TGA-DSC show that the initial weight loss at a temperature below $120^{\circ} \mathrm{C}$ refers to the evaporation of adsorbed water (figure 9). The slight increase in weight above $500^{\circ} \mathrm{C}$ corresponds to the transformation of the magnetite to hematite. ${ }^{31}$

Thermogram of the coated nanoparticles indicates three step weight loss, first step is due to desorption of water molecule at temperature below $120^{\circ} \mathrm{C}$. The second weight loss at $310^{\circ} \mathrm{C}$ and the third at $450^{\circ} \mathrm{C}$ is due to the decomposition of the physisorption and the chemisorptions of the coating agent at the surface of magnetite nanoparticles, respectively. ${ }^{32}$ The corresponding DSC curve of L-arginine and hexanoic acid coated nanoparticles exhibit an endothermic peak between $250^{\circ} \mathrm{C}$ and $270^{\circ} \mathrm{C}$ due to the oxidation and change in crystallinity of $\mathrm{Fe}_{3} \mathrm{O}_{4}$. Decomposition of L-arginine coated nanoparticles occurs at about $617^{\circ} \mathrm{C}$ producing an exothermic peak whereas hexanoic acid coated nanoparticles exhibited peak at $580^{\circ} \mathrm{C}$ proving that Larginine coated nanoparticles is more stable and oxidized at higher temperature than hexanoic acid coated nanoparticles. ${ }^{33}$

\subsection{In vitro cytotoxicity}

The anti-cancer activity of bare, acid coated and paclitaxel drug loaded L-arginine coated nanoparticles on human lung cancer A549 cell line was determined using MTT assay (figure 10). The assay measures the cell proliferation rate leading to apoptosis and reduces the cell viability. This is a colorimetric assay that measures the reduction of yellow MTT by mitochondrial succinate dehydrogenase. The MTT enters the cells and passes into the mitochondria where it is reduced to an insoluble, coloured (dark purple) formazan product. Percentage cell viability was determined using different concentration

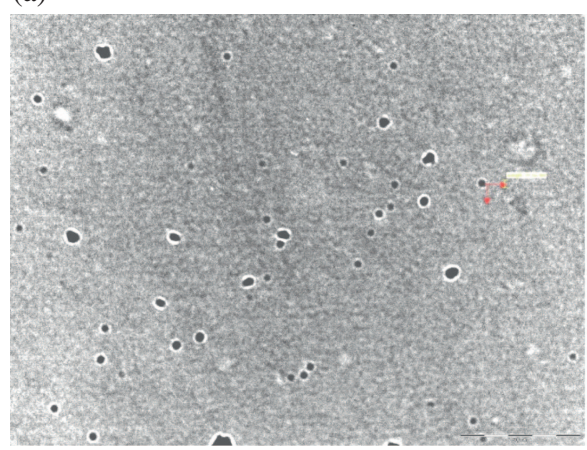

(b)

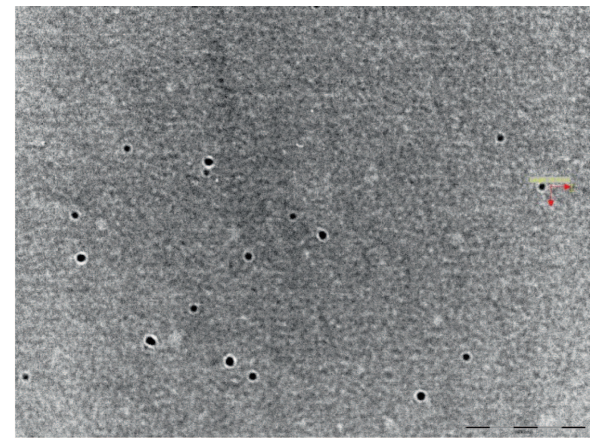

Figure 8. TEM images of (a) $\mathrm{Fe}_{3} \mathrm{O}_{4}$ nanoparticles; and (b) L-Arginine coated $\mathrm{Fe}_{3} \mathrm{O}_{4}$ nanoparticles. 

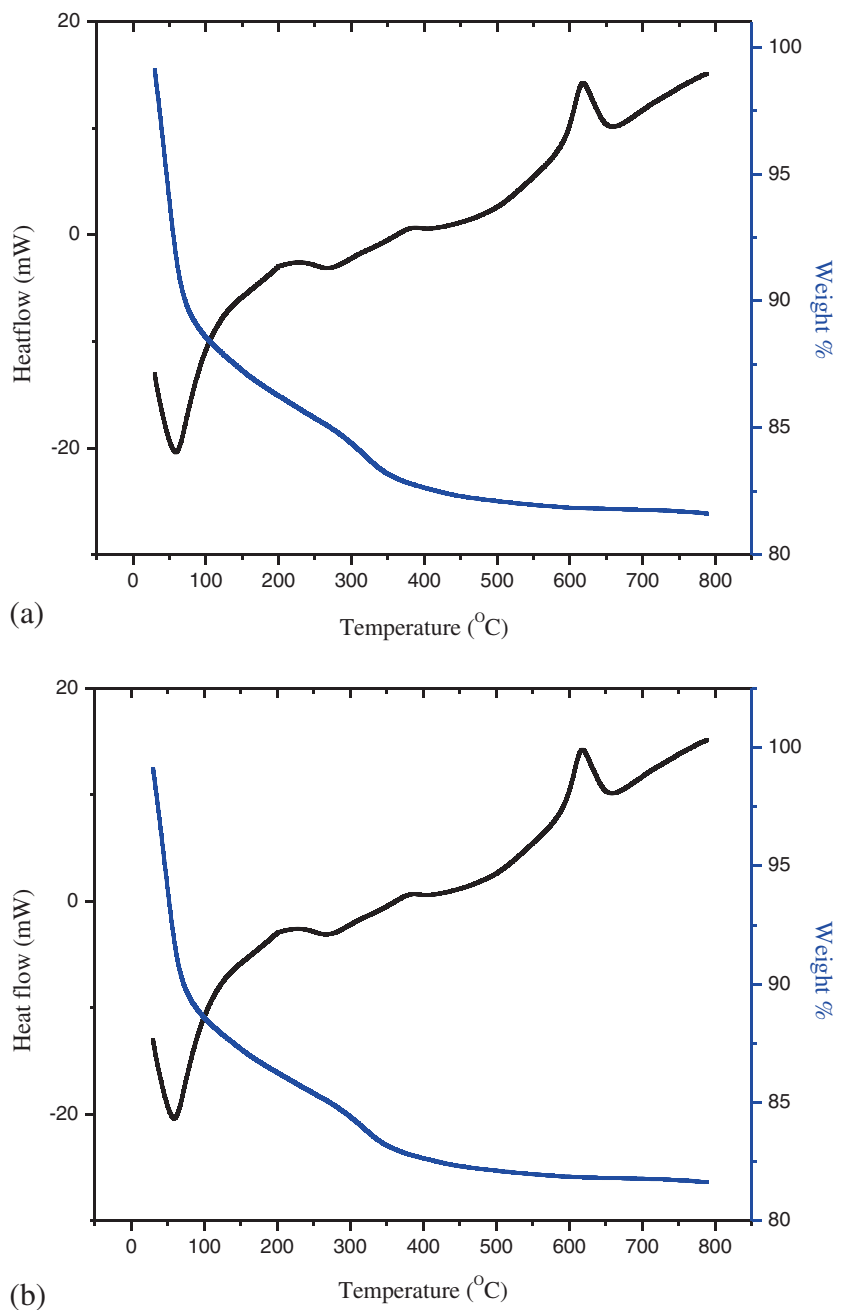

(b)

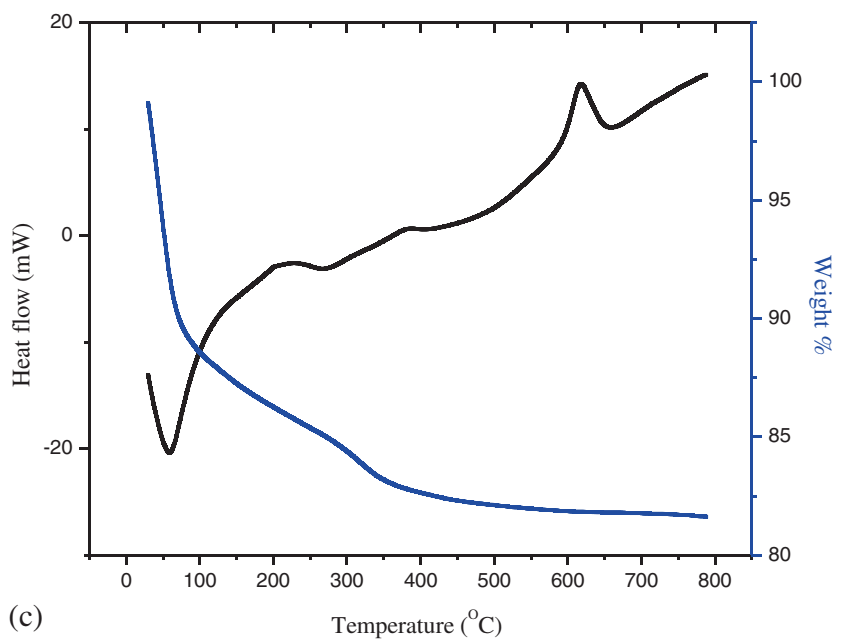

Figure 9. TGA-DSC analysis of (a) $\mathrm{Fe}_{3} \mathrm{O}_{4}$ nanoparticles; and nanoparticles coated with (b) Hexanoic acid; (c) L-Arginine.

of the bare and coated nanoparticles and the compatability of nanocarriers was determined graphically by $\mathrm{IC}_{50}$ values at an absorbance of $540 \mathrm{~nm}$ (table 2).
The $\mathrm{IC}_{50}$ value of bare and L-arginine coated iron oxide nanoparticles was found to be $31.2 \mu \mathrm{g} / \mathrm{mL}$, whereas that of ascorbic acid, hexanoic acid, salicylic acid and L-cysteine coated nanoparticles was $62.5 \mu \mathrm{g} / \mathrm{mL}$. The drug alone had $\mathrm{IC}_{50}$ value of $15.6 \mu \mathrm{g} / \mathrm{mL}$ whereas paclitaxel drug loaded L-arginine coated nanoparticles exhibited an $\mathrm{IC}_{50}$ value of $7.8 \mu \mathrm{g} / \mathrm{mL}$ (figure 11). The paclitaxel drug loaded on L-arginine coated nanoparticles were found to be more effective in inhibiting the growth of cancer cells when compared to the native paclitaxel. The magnetic force acting on the magnetic particle is proportional to the volume of the particle as the material is superparamagnetic. The magnetic force experienced by the smaller particles overcomes the force by the fluidic drag. Therefore, small particles have good permeability but poor retention. The anti-cancer drug paclitaxel has affinity to the targe $t$ cells and after grafting the drug to the surface magnetic nanoparticles can be internalized more rapidly. ${ }^{34}$

L-Arginine coated iron oxide nanoparticles produced significant cytotoxicity when compared to the other coated nanoparticles and resembled the bare iron oxide nanoparticles. The similarity in cytotoxicity of the bare and L-arginine functionalized magnetite nanoparticles may be due to the same particle size as already been reported. ${ }^{35}$ The anti-cancer activity of L-arginine coated iron oxide nanoparticles on non-cancer cell line (vero cell line) was studied. L-Arginine coated nanoparticles exhibited $80 \%$ of cell viability at a concentration of $31.2 \% \mu \mathrm{g} / \mathrm{mL}$ proving that it can be utilized as a promising platform for biomedical application (table 3).

L-Arginine coated nanoparticles with incubation at higher concentration caused significant cell death $(80 \%)$. However, it is expected that such a higher concentration of $1000 \mu \mathrm{g} / \mathrm{mL}$ will not be used for in vivo applications. Preliminary studies have proved that 15 $\mu \mathrm{g} / \mathrm{mL}$ of L-arginine was enough to cause cell death. Due to cytotoxic nature of paclitaxel treatment with drug loaded nanopartciles showed a decrease in cell viability of $51.2 \pm 0.1$ at $7.8 \mu \mathrm{g} / \mathrm{mL}$ concentration. ${ }^{5}$

\subsection{DNA fragmentation}

DNA fragmentation is a key feature of apoptosis, a type of programmed cell death. DNA is degraded into smaller fragments of oligonucleosomal size and is visualized as a laddering pattern in an agrose gel electrophoresis. ${ }^{36}$ Systematic cleavage of DNA to produce nucleosomal fragments of $200 \mathrm{bp}$ (or its multiples) is considered as characteristic of apoptosis. ${ }^{37}$ 


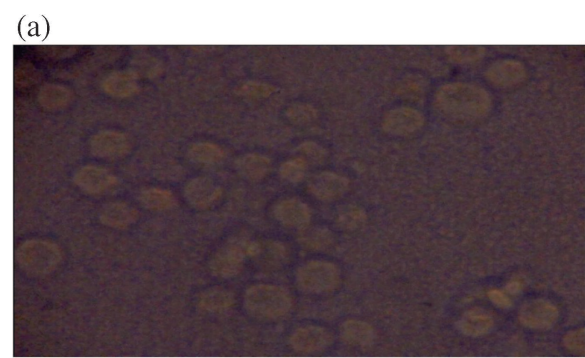

(c)

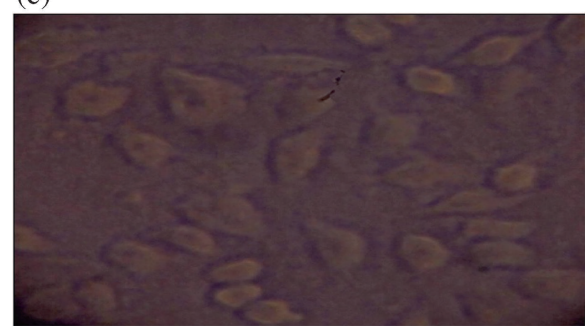

(e)

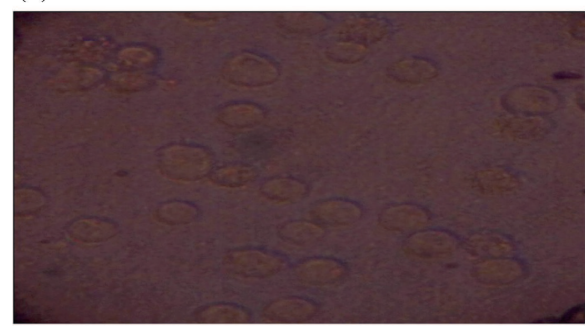

(g)

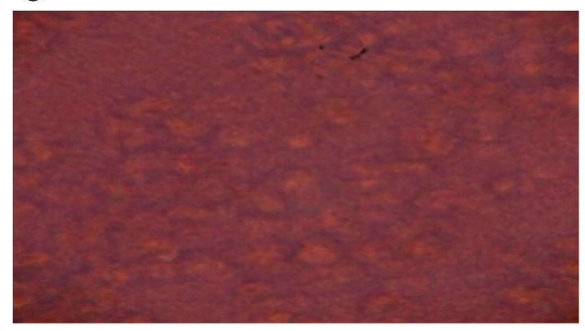

(b)

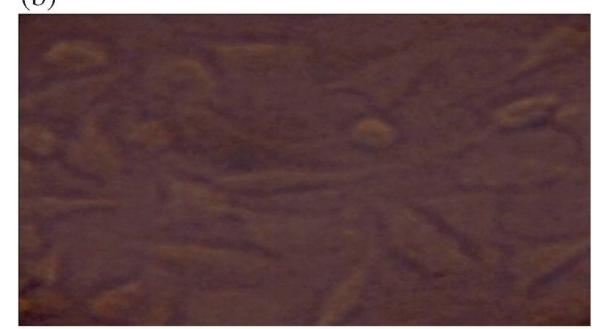

(d)

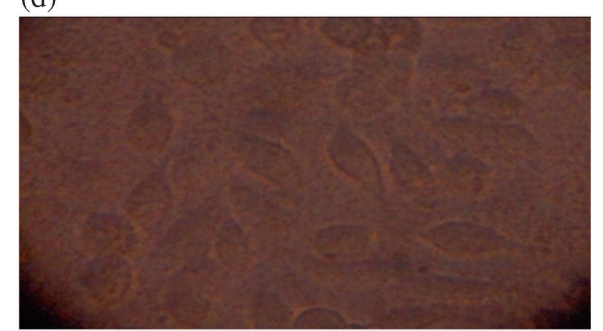

(f)

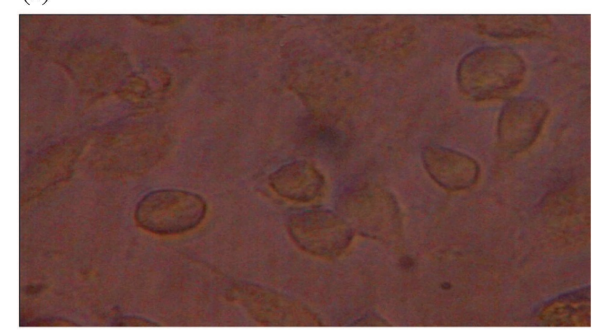

(h)

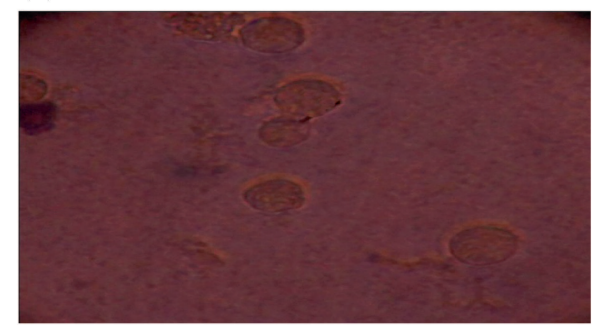

Figure 10. The morphological changes of human lung cancer cell line (A549) by MTT assay. (a) $\mathrm{Fe}_{3} \mathrm{O}_{4}$ nanoparticles; and nanoparticles coated with (b) Ascorbic acid; (c) Hexanoic acid; (d) Salicylic acid; (e) L-Arginine; (f) L-Cysteine; (g) Drug paclitaxel alone; and (h) Drug paclitaxel loaded L-arginine coated nanoparticles.

Table 2. $\mathrm{IC}_{50}$ values of bare and coated nanoparticles.

\begin{tabular}{lcc}
\hline Samples & IC $_{\mathbf{5 0}}$ values & Cell viability \\
\hline S & 31.2 & $49.2 \pm 0.20$ \\
S1 & 62.5 & $46.5 \pm 0.15$ \\
S2 & 62.5 & $46.5 \pm 0.15$ \\
S3 & 62.5 & $54.1 \pm 0.1$ \\
S4 & 31.2 & $53.5 \pm 0.15$ \\
S5 & 62.5 & $52.3 \pm 0.2$ \\
S6 & 15.6 & $53.5 \pm 0.15$ \\
S7 & 7.8 & $51.2 \pm 0.1$ \\
\hline
\end{tabular}

The $\mathrm{IC}_{50}$ value of L-arginine coated nanoparticles (31.2 $\mu \mathrm{g} / \mathrm{mL}$ ) proving its effectiveness in inhibiting A549 cell growth when compared with other coated nanoparticles. To elucidate whether the L-arginine coated nanoparticles inhibit proliferation through induction of apoptosis, DNA fragmentation was observed by agrose gel electrophoresis (figure 12). The breakdown of DNA molecules at a concentration of $1 \mathrm{mg} / \mathrm{mL}$ proved the inhibition of DNA replication, while untreated cells did not show any DNA fragmentation. Cell studies revealed that L-arginine functionalized nanoparticles was far more effective in inhibiting tumour proliferation by inducing apoptosis as indicted by the presence 


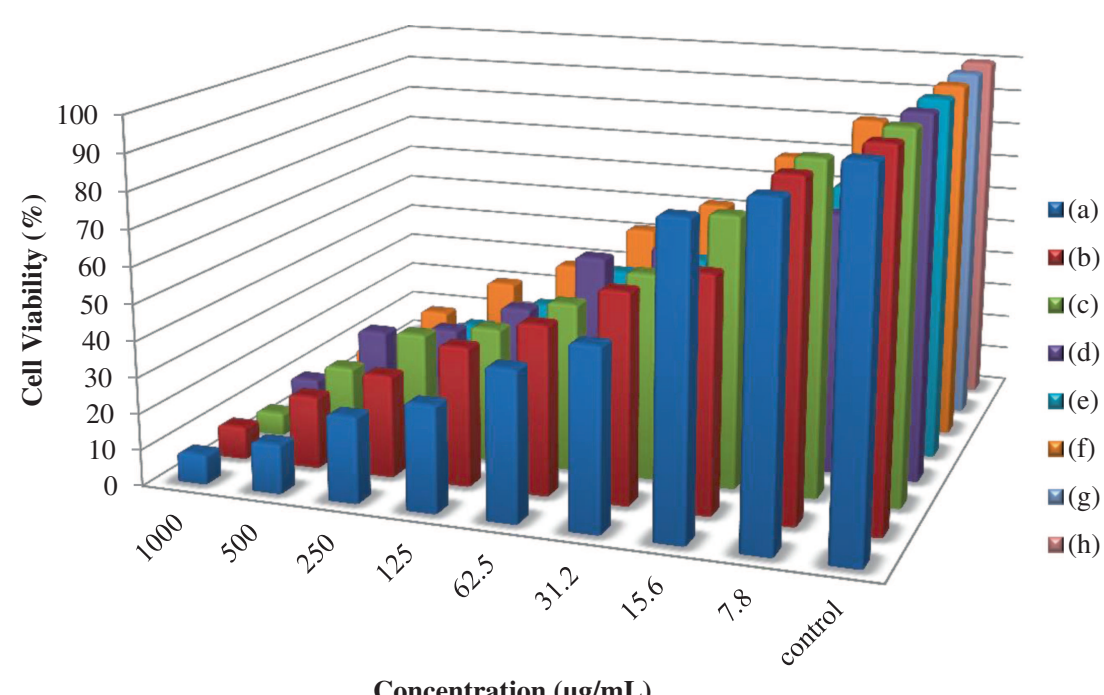

Figure 11. Percentage cell viability of nanoparticles at different concentration using MTT assay. (a) $\mathrm{Fe}_{3} \mathrm{O}_{4}$ nanoparticles; and nanoparticles coated with (b) Ascorbic acid; (c) Hexanoic acid; (d) Salicylic acid; (e) L-Arginine; (f) LCysteine. (g) Drug paclitaxel alone; and (h) Drug paclitaxel loaded L-arginine $\mathrm{Fe}_{3} \mathrm{O}_{4}$ coated nanoparticles.

Table 3. Percentage cell viability at different concentration of L-arginine coated nanoparticles for normal cell lines.

\begin{tabular}{lcccc}
\hline Sl. No. & $\begin{array}{c}\text { Concentration } \\
\mu \mathbf{g} / \mathbf{m L}\end{array}$ & Dilution & $\begin{array}{c}\text { Absorbance } \\
\mathbf{5 4 0} \mathbf{~ n m}\end{array}$ & $\begin{array}{c}\text { \% Cell } \\
\text { viability }\end{array}$ \\
\hline 1 & 1000 & Neat & 0.21 & 19.0 \\
2 & 500 & $1: 1$ & 0.43 & 39.0 \\
3 & 250 & $1: 2$ & 0.58 & 52.7 \\
4 & 125 & $1: 4$ & 0.79 & 71.8 \\
5 & 62.5 & $1: 8$ & 0.85 & 77.2 \\
6 & 31.2 & $1: 16$ & 0.88 & 80.0 \\
7 & 15.6 & $1: 32$ & 0.93 & 84.5 \\
8 & 7.8 & $1: 64$ & 1.03 & 93.6 \\
9 & control & - & 1.10 & 100 \\
\hline
\end{tabular}

of DNA fragmentation in treated cancer cells. Thus, the present study supports the anti-proliferative activity of L-arginine functionalized nanoparticles against A549 human lung cancer cell lines.

\section{Conclusions}

Superparamagnetic, bare and acid functionalized magnetite nanoparticles with efficient biocompatibility have been synthesized by co-precipitation method. XRD analysis suggested cubic spinal structure of the nanoparticles. Zeta measurements of L-arginine coated nanoparticles exhibited a lower potential and increase in the particle size due to the obstruction of intermolecular hydrogen bonding and positive charge of

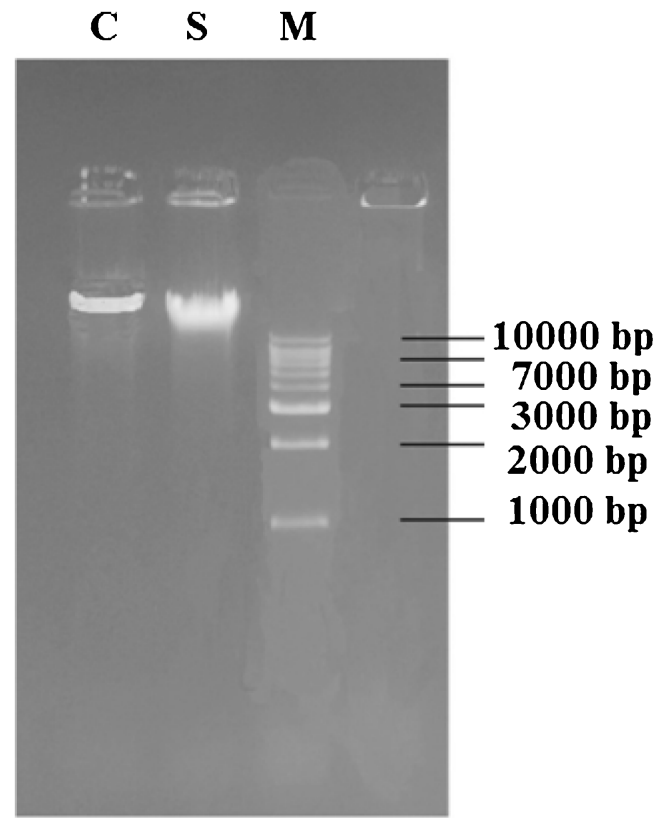

Figure 12. DNA fragmentation of A549 cells treated with $\mathrm{L}$-arginine coated magnetite nanoparticles. The image shows untreated cells $(\mathbf{C})$; cell treated with $\mathrm{L}$-arginine coated $\mathrm{Fe}_{3} \mathrm{O}_{4}$ nanoparticles (S) and the marker $(\mathbf{M})$. The untreated cells showed no evidence of fragmentation.

the amino group. The samples showed superparamagnetic behaviour with symmetric hysteresis and saturation magnetization. The TEM images revealed the crystalline size to be $31 \mathrm{~nm}$ for the bare iron oxide nanoparticles and $26 \mathrm{~nm}$ for $\mathrm{L}$-arginine coated iron 
oxide nanoparticles. Further, all the synthesized magnetite nanoparticles were tested for biomedical application as magnetic carriers. Cytotoxicity tests on A549 cell lines using MTT assay to find out \% cell viability for various concentrations were performed. Paclitaxel drug loaded with L-arginine nanoparticles resulted in enhanced cytotoxic effect leading to apoptosis. DNA fragmentation on A549 cell line with L-arginine coated iron oxide nanoparticles and control cells were examined. The control cells did not show any proliferation, whereas L-arginine coated iron oxide nanoparticles showed DNA fragmentation, proving that amino acid functionalized magnetite nanoparticles provided new opportunities for application in anti-cancer treatment.

\section{Acknowledgement}

DR thanks UGC, SERO, Hyderabad, for the financial support through the Minor Research Project Grant (No. F./MRP- 3984/11).

\section{References}

1. Tran N and Webster T J 2010 J. Mater. Chem. 208760

2. Petcharoen K and Sirivat A 2012 Mater. Sci. Eng. B 177 421

3. Mohapatra M and Anand S 2010 Int. J. Eng. Sci. Technol. 2127

4. Ozkaya T, Toprak M S, Baykal A, Kavas H, Koseoglu Y and Aktas B 2009 J. Alloys Compd. 47218

5. Rastogi R, Gulati N, Kotnala R K, Sharma U, Jayasundar R and Koul V 2011 Colloids Surf. B: Biointerfaces $\mathbf{8 2} 160$

6. Gupta A K and Gupta M 2005 Biomaterials 261565

7. Tan W L and Abubakar M 2006 J. Phys. Sci. 1737

8. Narain R, Gonzales M, Hoffmann A S, Stayton P S and Krishnan K M 2007 Langmuir 236299

9. Tomitaka A, Hirukawa A, Yamada T, Morishita S and Takemura Y 2009 J. Magn. Magn. Mater. 3211482

10. de Sousa M, van Raap M B F, Rivas P C, Zéils P M, Girardin P, Pasquevich G A, Alessandrini J L, Muraca D and Sánchez F H 2013 J. Phys. Chem. C 117 5436

11. Suri S S, Fenniri H and Singh B 2007 J. Occup. Med. Toxicol. 21

12. Andhariya N, Chudasama B, Mehta R V and Upadhyay R V 2011 J. Nanopart. Res. 131677

13. Lee K J, An J H, Shin J S, Kim D H, Yoo H S and Cho C K 2011 Curr. Appl. Phys. 11467
14. Bakshi H, Sam S, Rozati R, Sultan P, Islam T, Rathore B, Lone Z, Sharma M, Triphati J and Saxena R C 2010 Asian Pac. J. Cancer. Prev. 11675

15. Zheng Y Y, Wang X B, Shang L, Li C R, Cui C, Dong W J, Tang W H and Chen B Y 2010 Mater. Charact. 61 489

16. Kim D K, Zhang Y, Voit W, Rao K V and Muhammed M 2001 J. Magn. Magn. Mater. 22530

17. Lui X, Kaminski M D, Guan Y, Chen H, Lui H and Rosengart A J 2006 J. Magn. Magn. Mater. 306248

18. Chen C, Jiang X, Kaneti Y V and Yu A 2013 Powder Technol. 236157

19. Ghavami M, Koohi M and Kassae M Z 2013 J. Chem. Sci. 61347

20. Feng L, Cao M, Ma X, Zhu Y and Hu C 2012 J. Hazard. Mater. 217439

21. Karaoglu E, Baykal A, Senel M, Sozeri H and Toprak M S 2012 Mater. Res. Bull. 472480

22. Bhattacharya D, Sahu S K, Banerjee I, Das M, Mishra D, Maiti T K and Pramanik P 2011 J. Nanopart. Res. 9 4173

23. Giri J, Thakurta S G, Bellare J, Nigam A K and Bahadur D 2005 J. Magn. Magn. Mater. 29362

24. Karaagac O, Kockar H, Beyaz S and Tarisever T 2010 IEEE Trans. Magn. 463978

25. Sharifi I, Shokrollahi H, Doroodmand M M and Safi R 2012 J. Magn. Magn. Mater. 3241854

26. Thorek D L J, Chen A K, Czupryna J and Tsourkas A 2006 Ann. Biomed. Eng. 3423

27. Daou T J, Greneche J M, Pourroy G, Buathong S, Derory A, Ulhaq-Bouillet C, Donnio B, Guillon D and Begin-Colin S 2008 Chem. Mater. 205869

28. Wei Y, Han B, Hu X, Lin Y, Wang X and Deng X 2012 Procedia. Eng. 27632

29. Ni S, He D, Yang X and Li T 2011 J. Alloys. Compd. 509 L305

30. Lu W, Shen Y, Xie A and Zhang W 2010 J. Magn. Magn. Mater. 3221828

31. Yuana P, Fana M, Yanga D, He H, Liu D, Yuan A, Zhu J X and Chen T H 2009 J. Hazard. Mater. 166821

32. Grumezescu A M, Gestal M C, Holban A M, Grumezescu V, Vasile B S, Mogoanta L, Iordache F, Bleotu C and Mogosanu G D 2014 Molecules 195013

33. Huang C, Zhang H, Sun Z, Zhao Y, Chen S, Tao R and Liu Z 2011 J. Colloid Interface Sci. 364298

34. Kayal S and Ramanujan R V 2010 J. Nanosci. Nanotechnol. 101

35. Ebrahiminezhad A, Ghasemi Y, Rasoul-Amini S, Barar J and Davaran S 2012 Bull. Korean Chem. Soc. 333957

36. Guimarais V I, Guinon E G, Gabernet G, GareiaBelinchon G, Sanchez-Osuna M, Casanelles E, Comella J X and Yuste V J 2012 J. Biol. Chem. 2877766

37. Talib W H, Issa R A, Kherissat F and Mahasneh A M 2013 Br. J. Med. Med. Res. 3771 